\title{
Integrated reaction-extraction process for the hydroformylation of long-chain alkenes with a homogeneous catalyst
}

\author{
Kevin McBride ${ }^{\mathrm{a}}$, Nicolas Maximilian Kaiser ${ }^{\mathrm{b}}$, Kai Sundmacher ${ }^{\mathrm{a}, \mathrm{b}, *}$ \\ ${ }^{a}$ Max Planck Institute for Dynamics of Complex Technical Systems, Sandtorstrasse 1, 39106 Magdeburg, \\ Germany \\ ${ }^{b}$ Otto-von-Guericke University Magdeburg, Process Systems Engineering, Universitätsplatz 2, 39106 \\ Magdeburg, Germany
}

\begin{abstract}
A lingering issue with the hydroformylation of long-chain alkenes is the cost of catalyst leaching. One effective method to recover homogeneous catalysts is the use of thermomorphic solvent systems (TMS). However, catalyst leaching is still too high using the current solvents DMF and decane, limiting economic feasibility. This work presents extraction as a possible method for intensifying catalyst recovery when using a TMS for the hydroformylation of 1-dodecene. A thermodynamic model for determining the LLE of the solvent system and for catalyst leaching is developed for implementation within a process-wide optimization problem. Using this model, the optimal reactor design with an integrated downstream separation including the catalyst loss can be investigated in more detail. It is shown that in this process the reactor design strongly depends on catalyst recovery and that by using the proposed extraction cascade the process becomes economically viable and more robust in regards to reactor performance.

Keywords: Thermomorphic solvents, Homogeneous catalysis, Hydroformylation, Process optimization, Process intensification
\end{abstract}

\footnotetext{
*Corresponding author. sundmacher@mpi-magdeburg.mpg.de; Tel. +49 (0)391 6110-350; Fax: +49 (0)391 6110-353.
} 


\section{Introduction}

The chemical industry is faced with increasing demands for sustainable processes. A key technology in designing new processes with high selectivity and efficiency is homogeneous catalysis. Not only does homogeneous catalysis offer milder reaction conditions in addition to improved performance, but enables a plethora of new and different reactions to become realizable for industry (Behr and Johnen, 2010). Many of these new reactions make use of renewable feedstock not dependent on fossil feedstocks. One of these important reactions is the hydroformylation of long-chain alkenes. This reaction adds a formyl group and a hydrogen atom to opposing sides of a carbon-carbon double bond using hydrogen and carbon-monoxide gas in the presence of cobalt or rhodium based catalysts to form aldehydes. Aldehydes are important intermediates for alcohols, carboxylic acids, and amines leading to the production of detergents, plasticizers, surfactants, and other functionalized molecules. Preferably the more biodegradable, terminal aldehydes are desired due to their lower environmental impact (Wiese and Obst, 2006). Efficient chemical reactions with high selectivity for the linear aldehyde are preferable to an intensive downstream isomer separation usually accomplished by distillation. This ensures a lower energy demand for product purification and a higher atom efficiency in the reactor. This high selectivity for the terminal aldehyde is possible using special homogeneous catalysts comprised of active transition metals cobalt or rhodium enhanced with ligands (Cornils and Herrmann, 2003). More specifically, rhodium based catalysts with phosphine ligands show the highest levels of activity in the hydroformylation, leading to high product yield and selectivity for linear aldehydes.

The phosphite ligand Biphephos has been used quite frequently in homogeneous catalysis for hydroformylation (Behr et al., 2012; Brunsch and Behr, 2013). This is due to its high isomer selectivity for linear to branched aldehydes without a significant reduction in alkene conversion (Behr et al., 2012). Despite the high performance of Biphephos, one significant drawback is its price; even low levels (on the order of several ppm) of catalyst loss can lead 
to high process costs (McBride and Sundmacher, 2015). Not only is the ligand expensive, but the rhodium complex is as well. In hydroformylation studies, it is usually the rhodium leaching that is of primary concern. This bottleneck needs to be overcome before practical use of this efficient catalyst can be considered industrially (Behr and Neubert, 2012). In this case, the primary objective is to enhance the economical performance of the process by reducing catalyst leaching.

Many approaches to homogeneous catalyst recovery have been published in the literature including gas expanded liquids and supercritical fluids (Fang et al., 2007; Xie et al., 2013; Subramaniam et al., 2014), micellar sysetms or mass transfer agents, (Nowothnick et al., 2013; Pogrzeba et al., 2015; Schwarze et al., 2015), ionic liquids (Hintermair et al., 2007; Kunene et al., 2011), and membrane filtration (Janssen et al., 2010; Fang et al., 2011; Xie et al., 2015). Another practical method for homogeneous catalyst recovery is with convenient temperature controlled phase separation using a thermomorphic solvent system, or TMS (Behr and Fängewisch, 2002; Behr et al., 2008). A TMS consists of two or three solvents with varying polarities that allow one to control a mixture's phase behavior (whether it is homogeneous or biphasic) simply by altering the temperature. In the hydroformylation of alkenes it is necessary to eliminate mass transfer effects during the reaction requiring a single, homogeneous phase. Afterwards, the post-reaction mixture is separated into two phases when cooled. The catalyst distributes primarily into the more polar phase and the products and unreacted alkenes are principally found in the mostly nonpolar phase. This work focuses on extending and improving the use of a TMS consisting of dimethylformamide (DMF) as the polar solvent and decane as the nonpolar solvent in the hydroformylation of 1-dodecene.

Schäfer et al. (Schäfer et al., 2012) performed a series of experiments on the hydroformylation of 1-dodecene in a TMS of DMF and decane including liquid-liquid phase equilibrium measurements, reaction performance, and catalyst recycling. This successful implementation of the reaction and acquisition of useful information regarding phase be- 
havior led to an investigation into the reaction network (Markert et al., 2013) and the reaction kinetics (Kiedorf et al., 2014), which were later further improved through experimental validation of optimal reaction routes (Hentschel et al., 2015). The design of optimal reactors using this TMS for the hydroformylation of 1-dodecene (Hentschel et al., 2014) were investigated at the phenomena and molecular levels using the elementary process function (EPF) methodology (Freund et al., 2011). This work considered both the isolated reactor and the process wide design including downstream separation. Although the importance of catalyst leaching on the process economics is well known, it was not included in the integrated reactor and process design due to the absence of a model for describing the catalyst leaching. This led the authors to assume that the catalyst was completely recovered in the polar phase after separation in the decanter, although this is not the case. They postulated that were catalyst loss to be taken into account that the optimal process design would attempt to reduce the loss of catalyst by tuning the outlet composition of the reactor to one more conducive towards better phase separation. This is important because the product tridecanal enhances miscibility of the $\mathrm{DMF} /$ decane mixture thereby reducing the effectiveness of the TMS with higher conversion and selectivity.

Despite the promise of this TMS for catalyst recovery and product separation, it is still unsatisfactory for catalyst recovery in the current arrangement using a single decanter for economic reasons. McBride et al. (McBride et al., 2016) developed a framework for TMS design using quantum chemical calculations in order to identify potentially better TMS candidates based on their ability to recover the catalyst ligand. They found, remarkably, that mixtures of DMF with large alkanes $\left(\mathrm{C}_{8}-\mathrm{C}_{14}\right)$ were predicted as being top performing TMS systems for the hydroformylation of 1-dodecene with Biphephos as the catalyst ligand. These results were also experimentally validated including experiments with other candidate solvents identified during screening. The authors' assumption that the amount of leaching in the form of rhodium and the ligand are similar was shown to be acceptable during the experiments. The fact that a practical solvent better suited for catalyst recov- 
ery than DMF was not identified strongly suggests that a single stage separation using a TMS is not adequate alone for an economically feasible recovery of the rhodium-Biphephos catalyst.

The use of an integrated reactor-separator system for the hydroformylation of 1-dodecene using a coupled TMS and organic solvent nanofiltration (OSN) approach was presented (Dreimann et al., 2016a) as a possible mechanism to increase retention of the catalyst. They showed that low levels of leaching $(<1 \mathrm{ppm})$ are achieved using the addition of a membrane for a batch process. They also investigated continuous operation of the hydroformylation of 1-dodecene using toluene as a solvent and OSN for catalyst recovery (Dreimann et al., 2016b). They found that the membrane leads to low levels of leaching but that catalyst deactivation occurred within about one day of operation leading to lower activity and selectivity. The authors considered the possibility of extraction but state that the catalyst complex would become deactivated due to thermal stress at the required distillation temperatures for recovering the extraction solvent.

Instead of implementing a completely new method for enhancing catalyst recovery, it is proposed that by using subsequent extraction stages with fresh polar solvent (DMF) leaching can indeed be economically reduced. In this way the functionality of the TMS is extended by recovering the leached catalyst remaining in the nonpolar phases separated in previous stages. From a process design perspective, the introduction of extraction stages is relatively simple although additional mass separating agents and unit operations are required. The distillation temperatures required for recovering the extraction solvent can be circumvented using vacuum distillation to prevent catalyst deactivation. Such techniques are already necessary for the downstream separation of the aldehyde products. The approach suggested in this work shows that significant intensification of homogeneously catalyzed processes can be achieved by optimal combination of reactors with multiple catalyst extraction stages. The proposed process offers more flexibility in process conditions, should lower the overall energy usage, reduce waste, and drastically sink the operational 
costs.

The feasibility of the separation process is examined in the frame of an integrated reaction-extraction process for the hydroformylation of 1-dodecene. For this to be realized a model capable of predicting the partitioning behavior of the catalyst, as represented by the ligand Biphephos, must be created. This model must also provide solutions within an optimization problem. Once the LLE and catalyst partitioning can be reasonably predicted, the feasibility of a decanter cascade can be incorporated into the process design stage. At this point, the effect of integrated catalyst recovery and reactor performance can be evaluated by optimizing the total annualized cost of the process.

\section{Thermodynamic Model}

The method followed to generate the thermodynamic model used to describe the phase equilibrium and catalyst partitioning is depicted in Figure 1. The goal here is to design a model that can be used to calculate the phase equilibrium of a system given is molar composition and temperature. The model must also be functional within optimization problems as any such problem containing LLE calculations faces difficulty with convergence. For this reason a surrogate model is developed and used to solve the LLE internally during optimization. Whereas a linear surrogate model is used to alleviate a similar problem in (McBride and Sundmacher, 2015), a Kriging (Krige, 1951) model is chosen for this work. Kriging surrogate models have been the focus of much interest in simulation (Kleijnen, 2009). They have also been successfully used in process optimization, such as in modular flowsheet optimization (Caballero and Grossmann, 2008) and distillation column design (Quirante et al., 2015), for example. Use of this model to describe the decanters will alleviate the problem of solving the LLE within an optimization problem while providing the partitioning behavior of the catalyst. 


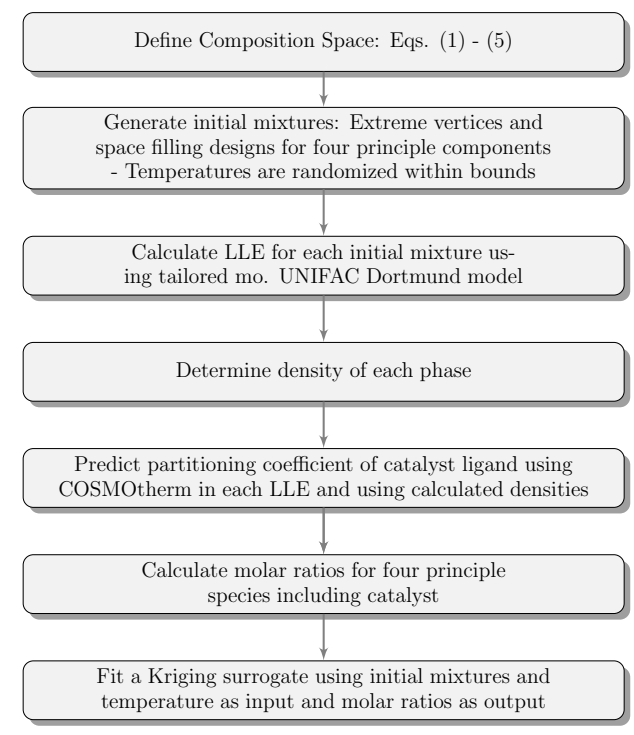

Figure 1: Method used to generate thermodynamic model including catalyst leaching for optimization.

\subsection{Phase Equilibrium}

The mixture considered here for phase separation consists of reactants, products, byproducts, and TMS solvents. In total, eight components need to be considered: DMF, decane, dodecane, 1-dodecene, iso-dodecene (a mixture of various internal dodecenes), tridecanal, 2-methyldodecanal, and the catalyst ligand Biphephos. In this work, the liquid-liquid equilibrium is modeled using the modified UNIFAC Dortmund (Weidlich and Gmehling, 1987) activity coefficient model with several of the binary interaction parameters refit to experimental data. This model is fully described in our previous publication and interested readers can reference it for more details (McBride and Sundmacher, 2015). This tailored thermodynamic model is very accurate for the four principle components found in the system considered: DMF, decane, 1-dodecene, and tridecanal. Two of the remaining components, iso-dodecene and 2-methyldodecanal, are isomers of 1-dodecene and tridecanal, respectively, and are predicted to have the same phase equilibrium behavior as their isomers. The small amount of dodecane is considered to behave similarly to decane. Thus, 
of the seven non-catalyst components, only four are used to describe the phase equilibrium.

\subsection{Catalyst Leaching}

Another main objective of the thermodynamic model is to be capable of predicting the partitioning behavior of the catalyst, as represented by the ligand Biphephos. Only the catalyst ligand is considered due to its usually higher concentration in the solution (in this case the ligand to $\mathrm{Rh}$ ratio is 5:1) and that the leaching of rhodium and that of the ligand are similar (Brunsch and Behr, 2013). Additionally, the cost of the ligand was found to affect the total process costs more significantly than the rhodium metal (McBride and Sundmacher, 2015).

A key factor why a model for catalyst leaching did not exist previously was a lack of data or an available method to model the catalyst thermodynamically. The use of modern quantum chemically based tools such as COSMO-RS allows for the thermodynamic modeling of large, complex molecules like Biphephos (Klamt et al., 2010). The molecular structure is developed using TURBOMOLE (2013) at the RI-DFT level of theory (Eichkorn et al., 1997) using the def2-TZVPD basis set (Rappoport and Furche, 2010). The resulting COSMO file encompasses all the necessary information for making solubility predictions of the Biphephos ligand using the software COSMOtherm (Eckert and Klamt, 2016).

The concentration of the catalyst in the reaction mixture is very low, being several orders of magnitude lower than that of 1-dodecene. Therefore COSMOtherm can be used to estimate partitioning coefficients which assumes infinite dilution. The distribution of the catalyst ligand can then be determined based on this partitioning coefficient. Since only the ratio between the two phases is needed, this prediction is sufficient for the following reaction-extraction optimizations.

\subsection{Data Generation}

Only compositions ensured to form two phases are considered for the surrogate model. This means the composition of the initial mixtures must be selected carefully to ensure 
that each mixture does indeed form two phases. Based on experimental data (Schäfer and Sadowski, 2012), it is known exactly where the binodal curve lies for the system DMF, decane, and tridecanal at $298.15 \mathrm{~K}$. Using this information, a region is chosen for typical compositions used in the TMS that are ensured to form two phases at all chosen separation temperatures from 253.15 to $293.15 \mathrm{~K}$. This composition space is shown in Figure 2. Equations 1 to 5 represent the constraints used to define this area. Since 1-dodecene does not enhance the miscibility of DMF and decane, its effect on the phase behavior is not as critical when ensuring that the post-reaction mixture is biphasic. All of the tridecanal found in the post-reaction mixture is converted from 1-dodecene, making the two species dependent. Therefore, the same composition constraints that apply to tridecanal are also used for 1-dodecene.

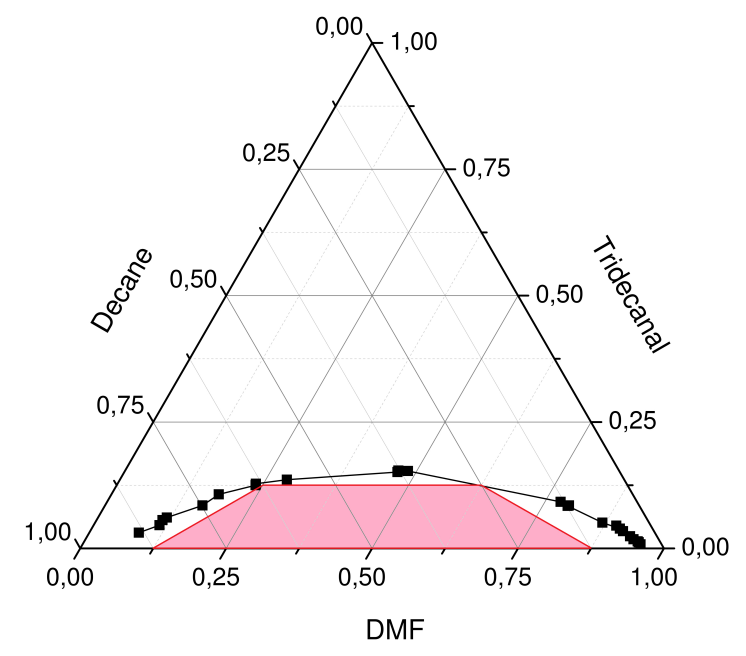

Figure 2: Post-reaction mixture constraints (within the shaded region under the binodal curve) used in modeling the surrogate model for determining LLE and catalyst partitioning. Experimental data at 298.15 K taken from Schäfer and Sadowski (2012). 


$$
\begin{aligned}
x_{\mathrm{DMF}}-x_{\text {tridecanal }} & \geq 0.125 \\
x_{\mathrm{DMF}}+2 \cdot x_{\text {tridecanal }} & \leq 0.875 \\
x_{\mathrm{DMF}}-x_{\text {dodecene }} & \geq 0.125 \\
x_{\mathrm{DMF}}+2 \cdot x_{\text {dodecene }} & \leq 0.875 \\
x_{\text {tridecanal }}+x_{\text {dodecene }} & \leq 0.125
\end{aligned}
$$

The next step is to generate the initial compositions for the surrogate model. This is done using the extreme vertices of the composition space as well as a space-filling design to ensure adequate spacing between sample points. There are a total of 29 vertices and a space-filling plan with 500 additional points is chosen. To safeguard against extrapolation of the Kriging model near the boundaries of the composition space, the LLEs formed with the compositions on the extreme vertices are calculated at $253.15,273.15$, and $293.15 \mathrm{~K}$ as well as for random temperatures for a total of 145 points. Each point in the space-filling design is now paired with a random temperature between 253.15 and $293.15 \mathrm{~K}$. This is twice repeated for a total of 1500 points.

Now the LLE for each composition and temperature can be calculated using the tailored modified UNIFAC model. Once the two phases in equilibrium for each point have been determined, the density of each phase is calculated using correlations published in (Yaws, 1998). This is done to ensure that accurate densities are used in COSMOtherm for the solubility predictions. Now the paritioning coefficient (see Eq. 6) of the catalyst is predicted using COSMOtherm for each biphasic system.

$$
\begin{array}{r}
\log _{10}\left(P_{j}^{(2,1)}\right)=\log _{10}\left(\exp \left(\left(\mu_{j}^{(1)}-\mu_{j}^{(2)}\right) / R T\right)\right) \\
=\log _{10}\left(x_{j}^{(1)} / x_{j}^{(2)}\right)
\end{array}
$$




$$
\theta_{i}^{\alpha}=\frac{n_{i}^{\alpha}}{n_{i}^{\alpha}+n_{i}^{\beta}} \quad i \in \mathrm{COM}
$$

The molar ratios for the four principle components used in the LLE calculations and for the catalyst ligand can now be calculated according to Eq. 7.

\subsection{Kriging Surrogate}

A Kriging model with a second order polynomial regression model and a Gaussian correlation model is chosen as the surrogate. In our preliminary investigations, the Kriging surrogates provided better results than when using linear functions. The main reason for this is the inclusion of the separation temperature as a variable into the surrogate instead of using a fixed temperature in the decanter. This makes representation through a linearly parameterized function difficult.

$$
\begin{aligned}
\hat{\theta}_{i}^{\alpha} & =K R\left(\hat{x}_{j}, T\right) \\
i & \in\{\mathrm{DMF}, \mathrm{C} 10 \mathrm{an}, \mathrm{nC} 13 \mathrm{al}, \mathrm{nC} 12 \mathrm{en}, \mathrm{BPP}\} \\
j & \in\{\mathrm{DMF}, \mathrm{C} 10 \mathrm{an}, \mathrm{nC} 13 \mathrm{al}\}
\end{aligned}
$$

The surrogate model uses the mole fraction vector of DMF, decane, and tridecanal plus the temperature as input variables. When considering the complete mixture in the optimization, the mole fractions of decane and dodecane, that of tridecanal and 2methyldodecanal, and those of 1-dodecene and iso-dodecene are added together. Due to the summation rule for mole fractions, only three of the principle components are necessary as input. The output variables are the five molar fractions of the four principle components and the catalyst ligand, represented by the vector $\hat{\theta}_{i}^{\alpha}$ as shown in Eq. 8. Again, the molar fraction of iso-dodecene is assumed to equal that of 1-dodecene, 2-methyldodecanal that of 1-tridecanal, and dodecane that of decane. 
Using the full space-filling design leads to surrogate models that require an unnecessarily large number of data points. Therefore it is not convenient to use the full space-filling designs, but to identify the best points to incorporate into the model and use the remaining data set for validation as a compromise. An iterative process is used starting with only the extreme vertices to generate the first surrogate model. The remaining points are then used for validation. The ten points in the validation set with the highest sum of relative errors are added to the sample set and a new Kriging model is generated. This process continues until either the overall relative error is less than $10^{-4}$ or the number of data points reaches the chosen maximum limit. Here, the overall relative error means the summation of the absolute value of the relative errors for all five predicted values from the Kriging model. In this case, the upper limit was chosen to be 550 data points. The Kriging model generated reached the maximum number of data points and had a maximum overall relative error of 0.0117 with an average overall relative error of 0.0021 . Very little change in overall error is observed during the last few iterations of the model.

A graphical comparison of the calculated molar ratios from our parameterized UNIFAC model and COSMOtherm partitioning coefficients with the predictions made using the Kriging surrogate are shown in Figure 3. As one can see, the fit is very good for the 5475 validation points plotted here. In the inset, a magnified view of the molar ratios near unity are shown in more detail. For the optimization, the Kriging surrogate must accurately reproduce the molar ratios for phase separation, especially in the case of the catalyst where ratios often come very close to unity. If the surrogate is ill-fitted, molar ratios greater than or equal to one may be predicted, which is inconvenient for finding realistic solutions when solving the NLP. Validation using randomly generated inlet compositions and temperatures within the boundaries of the sample data were used to verify that the surrogate model produces results less than one for all components.

Now that a reliable surrogate model for catalyst leaching has been developed, the effect of catalyst separation using a TMS and extraction in the hydroformylation of 1-dodecene 


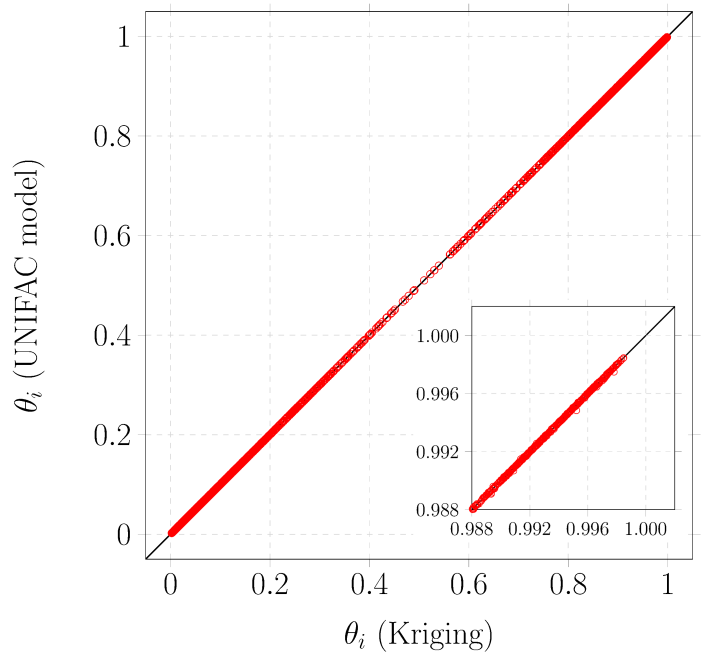

Figure 3: Comparison of calculated molar ratios using to the predicted molar ratios from the Kriging surrogate model. The inset shows that Kriging model can also accurately reproduce the critical results near unity.

can be included in process wide design problems.

\section{Process Flowsheet}

This work considers an integrated reaction and extraction design problem. Thus two important aspects for the flowsheet are to be considered: the reactor and the complete downstream separation including the proposed decanter cascade.

\subsection{Reaction}

The most important element for designing an optimal reactor is reliable reaction kinetics. In the hydroformylation of 1-dodecene, reaction pathways (Markert et al., 2013) and reaction kinetics were originally developed by Kiedorf et al. (Kiedorf et al., 2014). Since the original kinetics were determined using exclusively batch experiments, they were found to inaccurately describe systems operating under different operation modes. To amend this, additional batch, semi-batch, and perturbed batch experiments were conducted to 
increase the robustness of the reaction kinetics (Hentschel et al., 2015). Several parameters were updated and a sixth reaction, for the direct hydroformylation of 1-dodecene to 2-methyldodecanal, was added to the reaction network. The resulting reaction network is shown in Figure 4.

Reaction kinetic data and accompanying equations are found in the supplementary information. The reaction kinetics are represented by Eqs. S5 to S10, the temperature dependency of the reaction rate constants by Eq. S11, and the equilibrium constants used in reactions 2 and 3 are found using Eqs. S12 and S13. The catalyst equilibrium is represented by Eq. S14. The correlations for $\mathrm{H}_{2}$ and $\mathrm{CO}$ solubility in the liquid phase based on PCSAFT (Gross and Sadowski, 2001) calculations are also adapted from the work by Hentschel et al. (Hentschel et al., 2015). The equilibrium gas concentration is given by Eq. S15 and the liquid phase gas solubility by Eq. S16. The reaction kinetic parameters are listed in Table S7, the parameters for determining the equilibrium constants in Table S8, and the gas solubility parameters in Table S9.

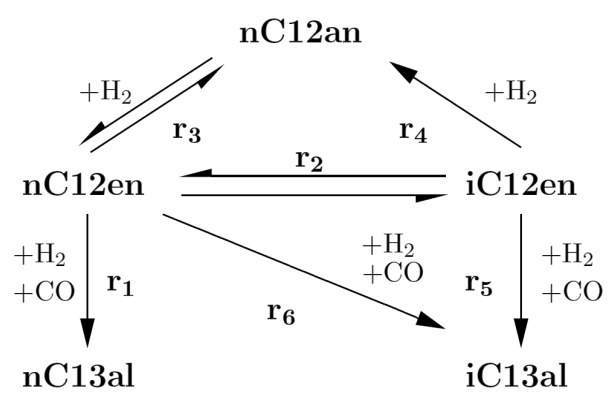

Figure 4: Updated reaction network for the hydroformylation of 1-dodecene proposed by Hentschel et al., from whom this figure is adopted (Hentschel et al., 2015).

The mass fraction of DMF and decane at the reactor inlet are maintained at 0.32 and 0.48, respectively. The reaction kinetics are valid for specific temperatures and pressures which form the bounds in the following optimizations: 


$$
\begin{gathered}
10 \text { bar } \leq P \leq 20 \text { bar } \\
368.15 \mathrm{~K} \leq T \leq 388.15 \mathrm{~K}
\end{gathered}
$$

\subsection{Reactor}

The reactor trajectories optimized using the elementary process function (EPF) methodology (Freund et al., 2011) lead to non-intuitive control strategies for temperature and $\mathrm{H}_{2} / \mathrm{CO}$ pressures along the reactor. In the hydroformylation of 1-dodecene, two major reaction zones could be identified: initially a region for quick formation of the desired linear aldehyde and the second region being dominated by reverse-isomerization of iso-dodecene, leading to additional linear and branched aldehyde formation. However, the regio- and chemo-selectivity behaviors are contrary. Hence, a cost optimization of the overall process was carried out (Hentschel et al., 2014) to evaluate the optimal reactor operation and the trade-offs with the downstream energy and unit size demands. In addition to the two identified reactions zones, seemingly high reaction times were also characteristic for optimal reactor configurations due to the lower significance of capital investment on the TAC.

With the updated kinetics, the same two reaction sections are again identified. The first region with high 1-dodecene concentration is preferably operated at the lower temperature bound and the reisomerization region at the upper temperature bound in order to accelerate the conversion of iso-dodecene back into 1-dodecene. Optimal pressure profiles for the new kinetics indicate that the first reaction zone is enhanced by an excess of $\mathrm{CO}$ to inhibit side reactions and an excess of $\mathrm{H}_{2}$ in the second reaction zone to reduce this inhibition in order to support the reverse-isomerization. Note, that this reactor arrangement is only optimal in case of a stand-alone reactor not coupled with recycle streams. One can see that the impact of the optimal gas profiles in each reaction zone on reactor performance is rather small and that the ratio of $\mathrm{CO}$ and $\mathrm{H}_{2}$ partial pressures are more important than their 
absolute values. Furthermore the second reaction zone, namely the reverse-isomerization, is enhanced by back-mixing for high conversions. For these reasons, the proposed reactor design is considered as a series of two reactors: a differential sidestream reactor (DSR) for the first reaction zone with low temperature and excess CO and a continuously stirred tank reactor (CSTR) for the second reaction zone with higher temperatures and excess $\mathrm{H}_{2}$ (see Fig. 5). The CSTR is assumed to have a comparatively longer residence time because of the relatively slow reverse-isomerization. For optimization purposes the DSR is modeled as a series of equal volume CSTRs with gas reactant dosing to maintain the pressure at the optimal level. In this manner, the proposed reactor series is modeled using Eqs. (11) to $(17)$.

$$
\begin{aligned}
\mathrm{C}_{\text {out }, r, i} & =\mathrm{C}_{i n, r, i}+C_{c a t, r} \tau_{r} M_{c a t} \sum_{j \in \mathrm{RCT}} v_{i, j} r_{j} \\
C_{i n, r, i} & =\frac{\dot{n}_{l i q, r, i}}{\dot{V}_{l i q, r}} \\
\dot{V}_{l i q, r} & =\sum_{i \in \mathrm{COM}} \frac{\dot{n}_{l i q, r, i} M_{i}}{\rho_{i}} \\
\rho_{i} & =a_{\rho, 0, i}+a_{\rho, 1, i} T \\
\tau_{r} & =\frac{V_{r}}{\dot{V}_{l i q, r}} \\
h_{i} & =h_{f, 0, i}\left(T_{0}\right)+\sum_{j=1}^{4} p_{C p, j, i}\left(T-T_{0}\right)^{j} \\
Q_{r} & =\sum_{i \in C O M}\left(n_{\text {out }, r, i} \cdot h_{\text {out }, i}-n_{\text {in }, r, i} \cdot h_{\text {in }, i}\right)
\end{aligned}
$$

\subsection{Separation}

\subsubsection{Decanters}

The separation processes are perhaps the most important in the flowsheet, especially the decanters. Now that a model is available for the LLEs within each decanter, the strong 


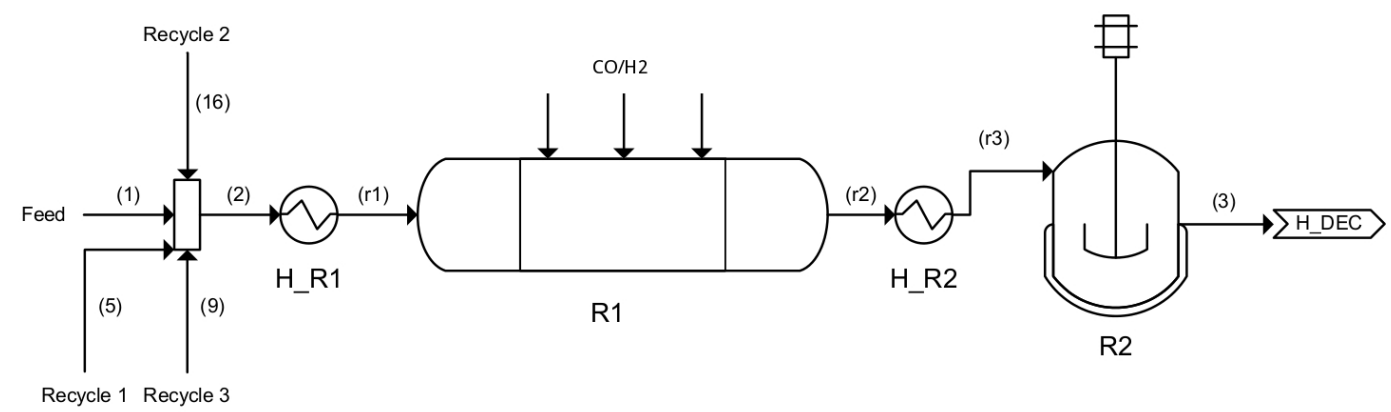

Figure 5: Depiction of the proposed reactor arrangement. This unit comes before the decanter feed shown in Figure 6 or Figure 7. The recycle streams shown in Figures 6 and 7 are integrated into the flowsheet at this point.

temperature and composition effects on catalyst leaching can be included in the optimization. The complete phase compositions formed within each decanter are determined using the Kriging model described in the previous section, given by Eqs. (18 and 19).

$$
\begin{array}{rl}
\dot{n}_{\mathrm{out}, \mathrm{s}, \mathrm{i}, \mathrm{p}}=\theta_{\mathrm{i}, \mathrm{s}}^{\alpha} \cdot \dot{n}_{\mathrm{i}, \mathrm{s}} & i \in \mathrm{COM}, s \in\{d 1, . ., d n\} \\
\dot{n}_{\text {out }, \mathrm{s}, \mathrm{i}, \mathrm{np}}=\left(1-\theta_{\mathrm{i}, \mathrm{s}}^{\alpha}\right) \cdot \dot{n}_{\mathrm{i}, \mathrm{s}} & i \in \mathrm{COM}, s \in\{d 1, . ., d n\}
\end{array}
$$

Here, $p$ and $n p$ represent the polar and nonpolar phases, respectively. The inlet streams to each decanter are specially designated as $d 1, d 2$, etc. Since the number of decanters is theoretically infinite, the stream $d n$ represents the inlet to the final decanter in the cascade.

The upper and lower bounds for the decanter cascade must be congruent with those used in generation of the thermodynamic model. The temperature in each decanter is the same except for that in the first decanter which is not part of the cascade.

$$
253.15 \mathrm{~K} \leq T_{s} \leq 293.15 \mathrm{~K}, \quad s \in\{d 1, . ., d n\}
$$

There are two different separation scenarios to consider: a separation following the TMS 
principle using a single decanter (case 1), and several cases using a counter current decanter cascade that requires extra polar solvent to be mixed with the inlet stream to the final decanter in the series. In the latter cases, an extra distillation column to recover the extraction solvent is required. The separation of the $\mathrm{CO}$ and $\mathrm{H}_{2}$ from the post reaction mixture is assumed to occur in a flash unit, which is not modeled here. This gas is assumed to be recycled back to the reactor and only the reactant gas consumed during the reaction is considered replaced.

\subsubsection{Scenario 1: Single Decanter}

The process considered in this analysis is shown in Figure 6. The post-reaction mixture $\left(\mathrm{S}_{3}\right)$ is fed to a heat exchanger $\left(\mathrm{H}_{D E C}\right)$ where the temperature is cooled from the reactor temperature to $300 \mathrm{~K}$ and then cooled further to the required separation temperature using a coolant in a second heat exchanger $\left(\mathrm{H}_{D 1}\right)$. The more polar of the two phases formed in D1 is to be eventually recycled back to the reactor feed and contains the majority of the catalyst used in the reaction. The non-polar phase is then heated to its bubble point temperature and fed to the reaction solvent distillation column (C2) where the unreacted reactants, various byproducts, and solvents are separated as the distillate from the aldehyde products which form the bottoms. The distillate of $\mathrm{C} 2$ is to be recycled back to the reactor feed and the aldehyde bottoms is heated to its bubble point and fed to the isomer column (C3) where the desired product n-tridecanal is separated as the bottoms from 2-methyldodecanal which forms the majority of the distillate. Altogether this separation process contains six heat exchangers, two columns, one decanter, and one refrigeration unit (not shown).

This is a commonly used arrangement developed in previous process design concepts for the hydroformylation of 1-dodecene using a TMS for catalyst recovery. A similar process is used in the optimization work done in (Hentschel et al., 2014) and in the operation of a miniplant (Zagajewski et al., 2014). 


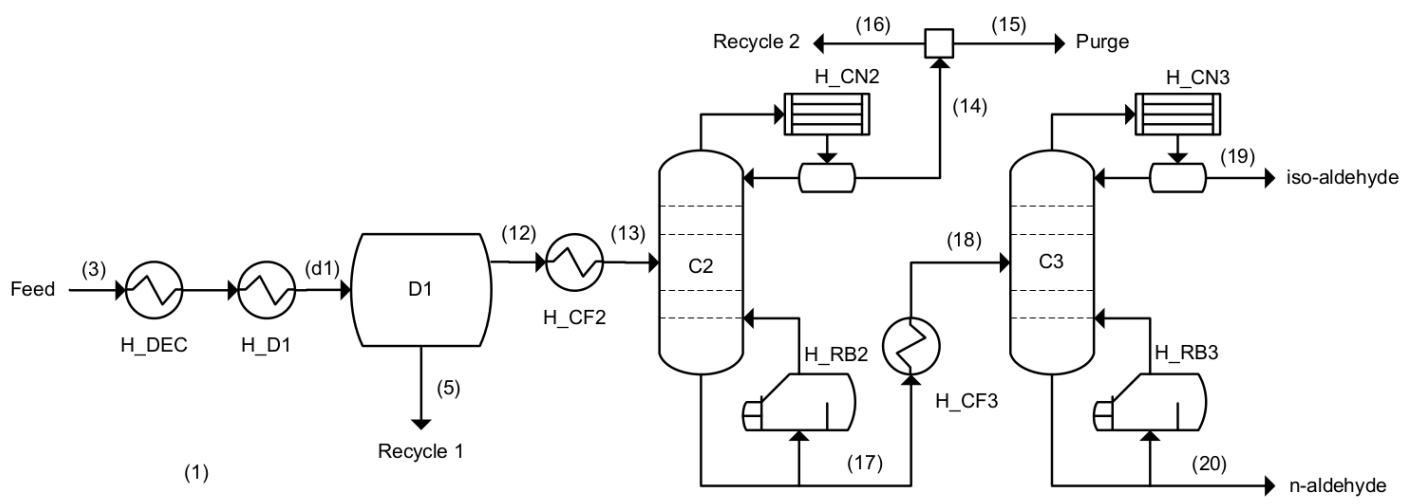

Figure 6: Flowsheet for the separation using a single decanter (D1). Distillation columns for the unreacted reactants and solvents (C2) and for the aldehyde separation (C3) are shown.

\subsubsection{Scenario 2: Liquid-Liquid Extraction}

The addition of extra separation stages in the form of decanters with excess polar solvent leads to a slightly more complicated process flowsheet. In Figure 7, the alteration to the flowsheet using a counter current cascade is shown. The cascade stages are labeled as D2 through DN, the final stage. Except for the additional decanters, heat exchangers, and extraction solvent column $(\mathrm{C} 1)$, the rest of the downstream processing remains the same as in case 1.

As before, the post-reaction mixture is initially cooled to the separation temperature using two heat exchangers. The polar phase in D1 is to be similarly recycled back to the reactor feed. The non-polar phase leaving the decanter is now fed to the next decanter in the cascade (D2). The polar phase from decanter D3 is also fed to D2 forming a new mixture which now separates into two phases. This process is applied to all subsequent decanters in the cascade except for the final decanter, where the non-polar phase is then fed into $\mathrm{C} 2$ as common in a counter current cascade (see DN in Figure 7 for clarification). The polar phase of D2 is heated to its bubble point temperature before being fed into the 
extraction solvent column (C1). This column is designed such that the distillate contains exactly the amount of solvent added to the cascade in order to avoid accumulation of extraction solvent in the system. The bottoms of $\mathrm{C} 1$ contains valuable catalyst recovered in the extraction and is to be recycled back to the reactor feed. The extraction solvent added to the final decanter in the cascade is not necessarily pure DMF but may contain a small amount of decane as well. This may occur because the purity and recovery of the extraction solvent are left as degrees of freedom in the optimization.

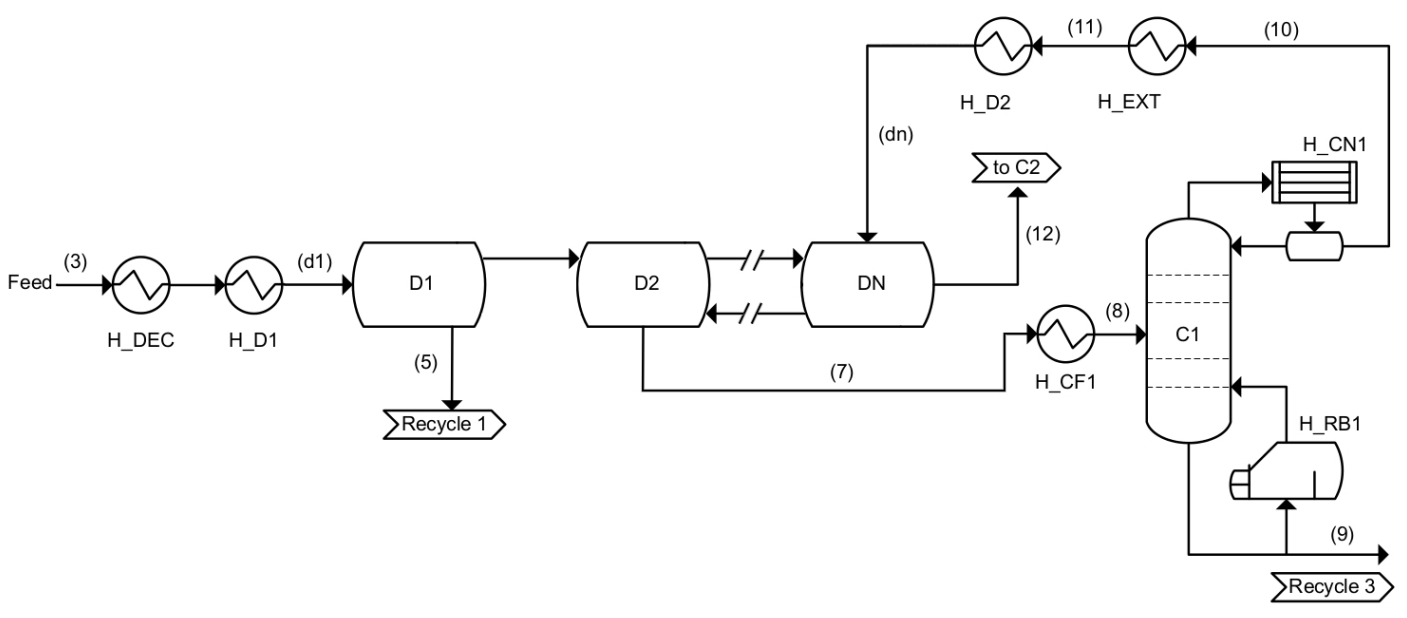

Figure 7: Counter current LL separation cascade and a solvent column (C1) to recover extraction solvent. The non-polar phase leaving the last decanter in the cascade is fed to column C2 as seen in Figure 6. The extra catalyst recovered using the cascade is recycled back to the reactor feed (recycle 3).

\subsubsection{Distillation Columns}

The proposed flowsheets contain two or three distillation columns depending on which scenario is considered. The first column, C1, is the extraction solvent column that separates the extra DMF added to the decanter cascade as the distillate. The bottoms of this column contains a mixture of all remaining components, most importantly recovered catalyst. The light key is DMF and the heavy key decane. Naturally in case 1 this column is not included in the flowsheet. The second column, C2, is the reaction solvent column. 
Here, the remaining reaction solvents, unreacted reactants, and dodecane and iso-dodecene byproducts are separated from the aldehydes and recycled back to the reactor. The light key in this column is iso-dodecene and the heavy key is 2-methyldodecanal. The third column, C3, is the isomer column used to separate 2-methyldodecanal, the light key, from the product tridecanal, the heavy key.

All columns are modeled using the Fenske-Underwood-Gilliand correlations. Column sizes and column flowrates can then be estimated using this short-cut method. The column pressure in $\mathrm{C} 1$ is assumed to be 246 mbar, as the catalyst becomes deactivated at temperature above 393.15. Because the tridecanal product will degrade at temperatures higher than $453 \mathrm{~K}$, the maximum pressure in $\mathrm{C} 2$ and $\mathrm{C} 3$ is limited to 88 mbar. The pressure drop is assumed to be $50 \%$ from the top to the bottom of the column, as done in (McBride and Sundmacher, 2015; Hentschel et al., 2014). All models used for the column design, vapor pressure correlations, mass balances, parameters, etc. are found in the supplementary information accompanying this article.

\section{Optimization}

The goal of this work is to identify the cost optimal reaction-extraction process for each of the cases mentioned in the previous section. Since there are many aspects to consider, such as the trade-off between increased capital and utility costs and decreased catalyst leaching, the use of cost functions becomes necessary. The cost functions developed by (Guthrie, 1969) are used with sizing estimations developed by (Biegler et al., 1997). The objective function (Eq. 21) is based on the three year total annualized cost of the process investment and production costs consisting of steam, cooling water, electricity, 1-dodecene feed, $\mathrm{H}_{2}, \mathrm{CO}$, and makeup solvents and catalyst. This objective is for cases considering

multiple decanters with only slight modification required for case 1 (see supplementary information for more detail).

Optimization variables are the decanter temperatures, coolant temperature, amount of 
extraction solvent added to the cascade, recovery fractions of the distillate and bottoms, reflux ratios in each distillation column, reactor temperatures, $\mathrm{CO}$ and $\mathrm{H}_{2}$ partial pressures in each reactor, reactor volumes, and the size of the purge stream. The product specifications include the production values assumed by (Hentschel et al., 2014): 10,000 tons $n$-tridecanal produced annually with at least $99.5 \%$ purity. The plant is assumed to operate for 330 days per annum. Based on past purchase information, the Biphephos ligand is assumed to be priced at $\$ 38.5 \mathrm{k}$ per kilogram (MOLISA GmbH). The cost of the Rhodium(I) dicarbonyl acetylacetonate precursor is estimated using the average spot price of rhodium for 2015 at $\$ 29562.70$ per kilogram.

$$
\begin{aligned}
& \min \mathrm{TAC}\left[\frac{\$}{\min }\right]=\left(C_{\text {capital }} / 3+C_{\text {production }}\right) \\
& \text { s.t. Reaction kinetics: Eqs. (S5)-(S14) } \\
& \text { Reactor: } \quad \text { Eqs. (9)-(16) } \\
& \text { Gas solubility: } \quad \text { Eqs. (S15)-(S16) } \\
& \text { Catalyst amount: Eqs. (S17)-(S18) } \\
& \text { Flowsheet: } \quad \text { Eqs. (S19)-(S56) } \\
& \text { Utilities: } \quad \text { Eqs. (S57)-(S75), (S120-S126) } \\
& \text { Unit Sizing: } \quad \text { Eqs. (S76)-(S109) } \\
& \text { Investment Eqs. (S110)-(S119) } \\
& \text { Mixture comp.: } \quad \text { Eqs. (1)-(5) } \\
& \text { Decanter: } \quad \text { Eqs. (17)-(19) } \\
& \text { Coolant: } \quad 230 \mathrm{~K} \leq T_{c d} \leq 283.15 \mathrm{~K} \\
& \text { Purge: } \quad 10^{-4} \leq x_{\text {purge }} \leq 0.1 \\
& \text { Extraction Solvent: } 0 \leq \sum_{i} \dot{n}_{i, 11} \leq 100 \\
& \text { Reactor Volume: } \quad 1 \leq V_{r} \leq 10^{4}
\end{aligned}
$$


All additional equations and parameters used in the integrated reaction-extraction process are found in the supplementary information and are designated in Eq. 21 with an S. All scenarios mentioned in this section, as well as the integrated reaction-extraction problems later, are implemented as separate NLPs in AMPL and solved using the solver CONOPT $3.14 \mathrm{~V}$ on a PC with one Intel Core ${ }^{\mathrm{TM}} \mathrm{i} 5-3570 \mathrm{CPU}$ at $3.40 \mathrm{GHz}$, a memory of 8 GB, and running on the Kubuntu 12.04 operating system.

The total number of cases considered is dependent upon the rate of catalyst recovery and the trend in the TAC. If catalyst leaching becomes nearly zero, then further separation stages may be unnecessary. On the other hand, once a minimum in the TAC has been established, then further separation stages simply add to the process costs rather than decrease it. Once this occurs, the optimizations will cease. One reference case similar to case 1 but without consideration of catalyst leaching costs in the optimization is used for comparison purposes.

\section{Results and Discussion}

In total seven different process optimizations were conducted: six different cases using one to six decanters and one reference case. No more than six decanters in the cascade are necessary since almost no catalyst leaching occurs with six separation stages and that the overall TAC using six decanters increases from the minimum found using five. Table 1 contains the detailed cost analysis for all cases. All costs are given in dollars per kilo mole product.

\subsection{Separation Performance}

It is immediately clear that additional separation stages strongly affect the process cost, decreasing it substantially in all cases where multiple decanters are used. Most noticeably, and expectedly, the largest changes are seen in the production costs. This is primarily due to the reduction in catalyst leaching, which although quite low in case $1(<1 \%)$, 
Table 1: Comparison of production and capital costs for each integrated reaction-extraction case. All costs presented here are $\$ / \mathrm{kmol}$ product except for the $\%$ Recovered referring to the amount of catalyst recovered.

\begin{tabular}{lccccccc}
\hline & Case 1 & Case 2 & Case 3 & Case 4 & Case 5 & Case 6 & Reference \\
\hline Decane & 0.07 & 2.12 & 2.82 & 3.16 & 3.30 & 3.32 & 2.14 \\
DMF & 0.01 & 0.21 & 0.51 & 0.81 & 0.89 & 0.90 & 0.47 \\
1-Dodecene & 681.67 & 683.40 & 686.13 & 687.26 & 687.71 & 687.76 & 682.96 \\
$\mathrm{H}_{2}$ & 4.11 & 4.12 & 4.14 & 4.14 & 4.15 & 4.15 & 4.11 \\
$\mathrm{CO}$ & 4.09 & 4.10 & 4.11 & 4.12 & 4.12 & 4.12 & 4.10 \\
& & & & & & & \\
Catalyst & 334.68 & 8.63 & 1.51 & 0.30 & 0.02 & 0.00 & 1792.72 \\
\% Recovered) & 99.3595 & 99.9829 & 99.9965 & 99.9993 & 99.9999 & 100.0000 & 96.5692 \\
Steam & 26.42 & 26.85 & 22.34 & 20.28 & 19.75 & 19.69 & 24.71 \\
Cooling water & 3.64 & 2.27 & 2.25 & 2.09 & 2.02 & 2.02 & 2.90 \\
Electricity & 4.68 & 1.98 & 0.34 & 0.20 & 0.19 & 0.19 & 0.24 \\
& & & & & & & \\
Production & 1059.36 & 733.68 & 724.15 & 722.36 & 722.15 & 722.14 & 2511.21 \\
Capital & 49.85 & 37.04 & 32.30 & 31.60 & 31.51 & 31.53 & 31.72 \\
Total & 1109.21 & 770.73 & 756.45 & 753.96 & 753.66 & 753.67 & 2542.93 \\
Total (no cat) & & & & & & & 750.20 \\
\hline
\end{tabular}

Table 2: Temperatures $[\mathrm{K}]$ in each decanter and for the coolant in each case.

\begin{tabular}{lccc}
\hline & $\mathrm{T}_{d 1}$ & $\mathrm{~T}_{d 2, . ., d n}$ & $\mathrm{~T}_{c d}$ \\
\hline Case 1 & 253.15 & & 241.82 \\
Case 2 & 280.94 & 253.16 & 242.86 \\
Case 3 & 293.15 & 278.01 & 266.93 \\
Case 4 & 293.15 & 290.50 & 276.32 \\
Case 5 & 293.15 & 291.63 & 276.52 \\
Case 6 & 293.15 & 291.71 & 276.53 \\
Reference & 293.15 & & 277.41 \\
\hline
\end{tabular}


Table 3: Percentage costs of catalyst in each case as part of the total TAC, the total production costs, and the production costs not including 1-dodecene.

\begin{tabular}{lccccccc}
\hline Catalyst Cost \% & Case 1 & Case 2 & Case 3 & Case 4 & Case 5 & Case 6 & Ref. \\
\hline TAC & 30.17 & 1.12 & 0.20 & 0.04 & 0.00 & 0.00 & 70.50 \\
Production & 31.59 & 1.18 & 0.21 & 0.04 & 0.00 & 0.00 & 71.39 \\
Production w/o 1-dodecene & 88.61 & 17.16 & 3.98 & 0.85 & 0.07 & 0.00 & 98.06 \\
\hline
\end{tabular}

Table 4: Distillation column dimensions, recoveries, heating duties, and cooling duties.

\begin{tabular}{lcccccc}
\hline C1 & $\mathrm{H}(\mathrm{m})$ & $\mathrm{D}(\mathrm{m})$ & Recovery & Stages & $\mathrm{Q}_{\mathrm{reb}}(\mathrm{kW})$ & $\mathrm{Q}_{\mathrm{con}}(\mathrm{kW})$ \\
\hline Case 1 & $/$ & $/$ & $/$ & $/$ & $/$ & $/$ \\
Case 2 & 10.35 & 0.51 & 0.69225 & 8.26 & 114.44 & -113.46 \\
Case 3 & 10.32 & 0.49 & 0.69170 & 8.20 & 104.63 & -102.74 \\
Case 4 & 13.73 & 0.47 & 0.84522 & 13.88 & 96.53 & -91.27 \\
Case 5 & 14.85 & 0.46 & 0.88141 & 15.75 & 93.86 & -87.33 \\
Case 6 & 14.95 & 0.46 & 0.88438 & 15.92 & 93.50 & -86.86 \\
Reference & $/$ & $/$ & $/$ & $/$ & $/$ & $/$ \\
\hline C2 & $\mathrm{H}(\mathrm{m})$ & $\mathrm{D}(\mathrm{m})$ & Recovery & Stages & $\mathrm{Q}_{\mathrm{reb}}(\mathrm{kW})$ & $\mathrm{Q}_{\mathrm{con}}(\mathrm{kW})$ \\
\hline Case 1 & 21.55 & 2.66 & 0.94607 & 26.92 & 1555.99 & -1208.43 \\
Case 2 & 33.98 & 2.68 & 0.99617 & 47.64 & 1580.69 & -1225.19 \\
Case 3 & 32.02 & 2.50 & 0.99478 & 44.37 & 1398.24 & -1077.32 \\
Case 4 & 30.44 & 2.42 & 0.99308 & 41.73 & 1322.34 & -1014.40 \\
Case 5 & 29.86 & 2.39 & 0.99228 & 40.77 & 1289.70 & -988.52 \\
Case 6 & 29.79 & 2.39 & 0.99217 & 40.65 & 1285.80 & -985.45 \\
Reference & 34.82 & 2.81 & 0.99688 & 49.03 & 1767.40 & -1361.09 \\
\hline C3 & $\mathrm{H}(\mathrm{m})$ & $\mathrm{D}(\mathrm{m})$ & Recovery & Stages & $\mathrm{Q}_{\mathrm{reb}}(\mathrm{kW})$ & $\mathrm{Q}_{\mathrm{con}}(\mathrm{kW})$ \\
\hline Case 1 & 55.98 & 1.06 & 0.99975 & 84.29 & 224.82 & -223.13 \\
Case 2 & 54.17 & 1.09 & 0.99952 & 81.29 & 233.79 & -240.22 \\
Case 3 & 54.08 & 1.09 & 0.99950 & 81.14 & 235.13 & -242.03 \\
Case 4 & 54.05 & 1.09 & 0.99950 & 81.09 & 235.58 & -242.54 \\
Case 5 & 54.05 & 1.09 & 0.99950 & 81.08 & 235.72 & -242.70 \\
Case 6 & 54.04 & 1.09 & 0.99950 & 81.07 & 235.74 & -242.71 \\
Reference & 53.95 & 1.08 & 0.99950 & 80.92 & 233.17 & -239.33 \\
\hline
\end{tabular}




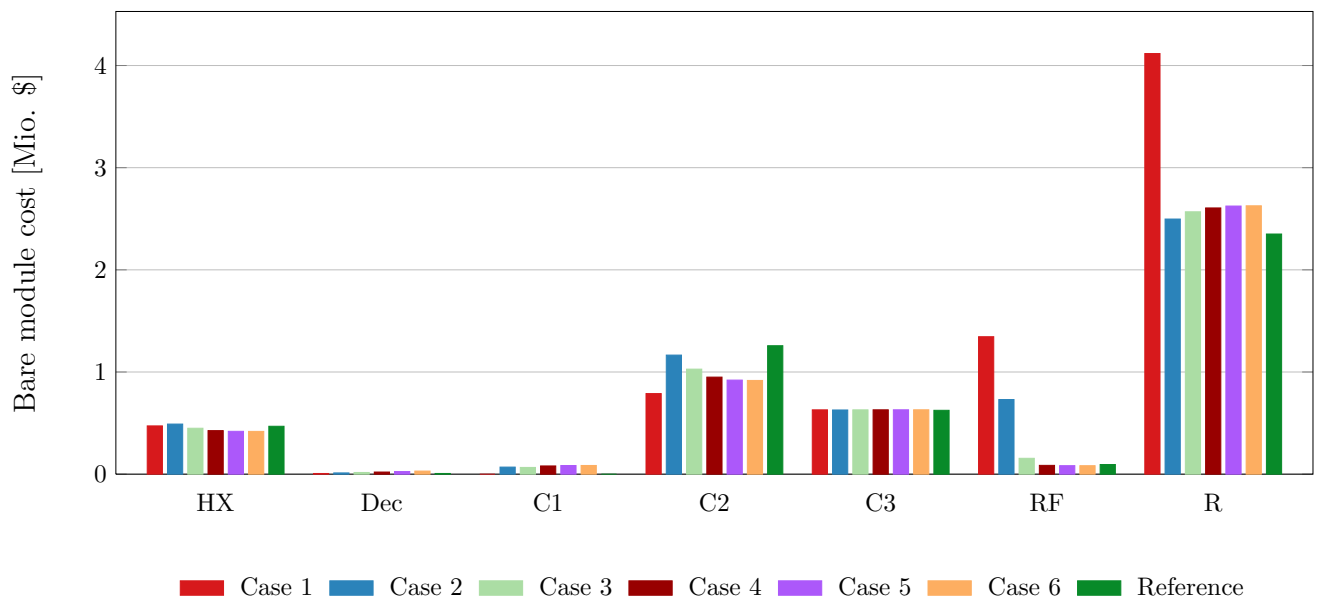

Figure 8: Investment cost comparison for the optimal separation process in each case. Costs are shown for the heat exchangers (HX), decanters (Dec), distillation columns (C1, C2, and C3), refrigeration (RF), and reactors $(\mathrm{R})$.

contributes significantly to the cost at about $30.4 \%$ of the TAC. With the addition of one extra extraction stage as in case 2 , the catalyst recovery is predicted to be above $99.98 \%$, or only $1.13 \%$ of the TAC, slightly more than that of the reactant gases required. The catalyst leaching in cases 3 through 6 still decreases, but the overall impact on the process cost is small after the third decanter. The cost of 1-dodecene increases as a result of the lower $\mathrm{n} /$ iso ratios leading to more 2-methyldodecanal product, although this influence is small. The increase in solvent makeup is due the increasing purge fractions with an increase in the number of separation stages. Although the purge increases, the amount of 1-dodecene, iso-dodecene, and dodecane lost here stays relatively the same in each case.

In case 6 it can be seen that a near complete recovery of the catalyst leads to no visible change in process economics. As the number of separation stages increases, the capital costs tend to decrease as well due to the decrease in size of the reactor between case 1 and case 2 and the reduced need for refrigeration as the decanter temperatures increase. With four or more decanters the separation temperatures tend to lie near the upper bound (see Table 2). Thus, the strong temperature dependency of the catalyst leaching becomes 
irrelevant as more opportunities for recovery by extraction become available. This reduces the cost of refrigeration from being high in cases 1 and 2 to becoming inconsequential in the remaining cases. The reduction in refrigeration is also leads to lower utility costs for electricity as the number of decanters increases.

Naturally in the reference case where the cost of the catalyst is ignored, the overall process cost is quite high once catalyst leaching is calculated. The catalyst cost would consume $70.5 \%$ of the TAC. Here the separation in the decanter is not as critical and hence the separation temperature is the maximum. Also, the post reaction mixture contains more tridecanal than in case 1 , because the poorer phase separation and catalyst recovery brought about by higher tridecanal concentrations does not significantly affect cost for this case. The reactor size is also not critical because the outlet composition of the reactor does not need to consider catalyst leaching.

Once the need for refrigeration decreases after case 3, the trade-off between reactor performance and size with the reaction solvent column (C2) size and utility usage becomes the dominant trade-off. This column is quite large compared to the others due to the large amount of solvents that need to be vaporized (see Table 4). resulting in a large vapor flow that requires a wider column diameter. Also, the heating duty in the reboiler and cooling duty in the condenser are substantially higher than in the other columns. As the decanter cascade increases in size, the size of $\mathrm{C} 2$ decreases in size and the reactor becomes larger. This occurs as a result of the lower levels of dodecane used in the reactor which lead to a lower overall amount of solvent due to the restriction that the TMS compromises $80 \%$ of the mass found in the reactor feed. The overall molar flowrate decreases from 45.51 $\mathrm{mol} / \mathrm{s}$ in case 1 to $33.82 \mathrm{~mol} / \mathrm{s}$ in case 6 as a consequence (see Figure 9). This would normally lead to a reduction in reactor size, but because of increasing residence times the reactor actually increases in volume. This reduction in the amount of reaction solvent that needs to be vaporized also further decreases the size of the column $\mathrm{C} 2$. The reduction in the amount of steam required in the process is directly related to this decrease in column 
size. Additionally, due to the increased temperature of the decanter cascade, the amount of steam necessary to bring the feed to column C2 up to its bubble point decreases. This also results in lower steam costs.

The size of the isomer column, C3, does not seem to be affected strongly by the type of separation used as the $\mathrm{n} /$ iso ratio does not vary much case to case. A slight increase in column size is seen as the $\mathrm{n} /$ iso ratio decreases though, as the volumetric flowrate in the column increases, requiring a larger diameter. However, this small change is insignificant and the potential for improving the process economics here is not very high.

Comparatively, the investment and production costs for the extraction solvent column, $\mathrm{C} 1$, are not high. The cost of adding this process unit compared to the reduction in refrigeration costs and catalyst leaching is very low, making it a recommended investment. The cost of this column tends to increase with the number of decanters used in the cascade although the amount of solvent needed for the cascade decreases, as shown in Figure 10. It does however slightly decrease from case 2 to case 3 due to the shrinking size of the column height and diameter. Beginning with case 4, the amount of extraction solvent drops significantly leading to a necessary, higher recovery fraction in C1. Thus, the column diameter continues to decrease but the height of the column increases leading to an overall more expensive column.

\subsection{Reactor Performance}

An interesting aspect of the optimization is that in each case, the second reactor $\mathrm{R} 2$, the CSTR, is not used. Instead, both reaction zones take place in R1 in one large DSR. Large reactors with high residence times are required for high selectivity. In several other local optima with higher total process costs, the CSTR was used for the reverse-isomerization while the DSR was used only for the relatively quick first reaction zone as predicted. Differences in cost are slight and may be influenced by the correlations for the reactor costs. In a technical realization it is more reasonable to use a large CSTR for the reverseisomerization. Although considering the overall effect of capital cost on the process, any 

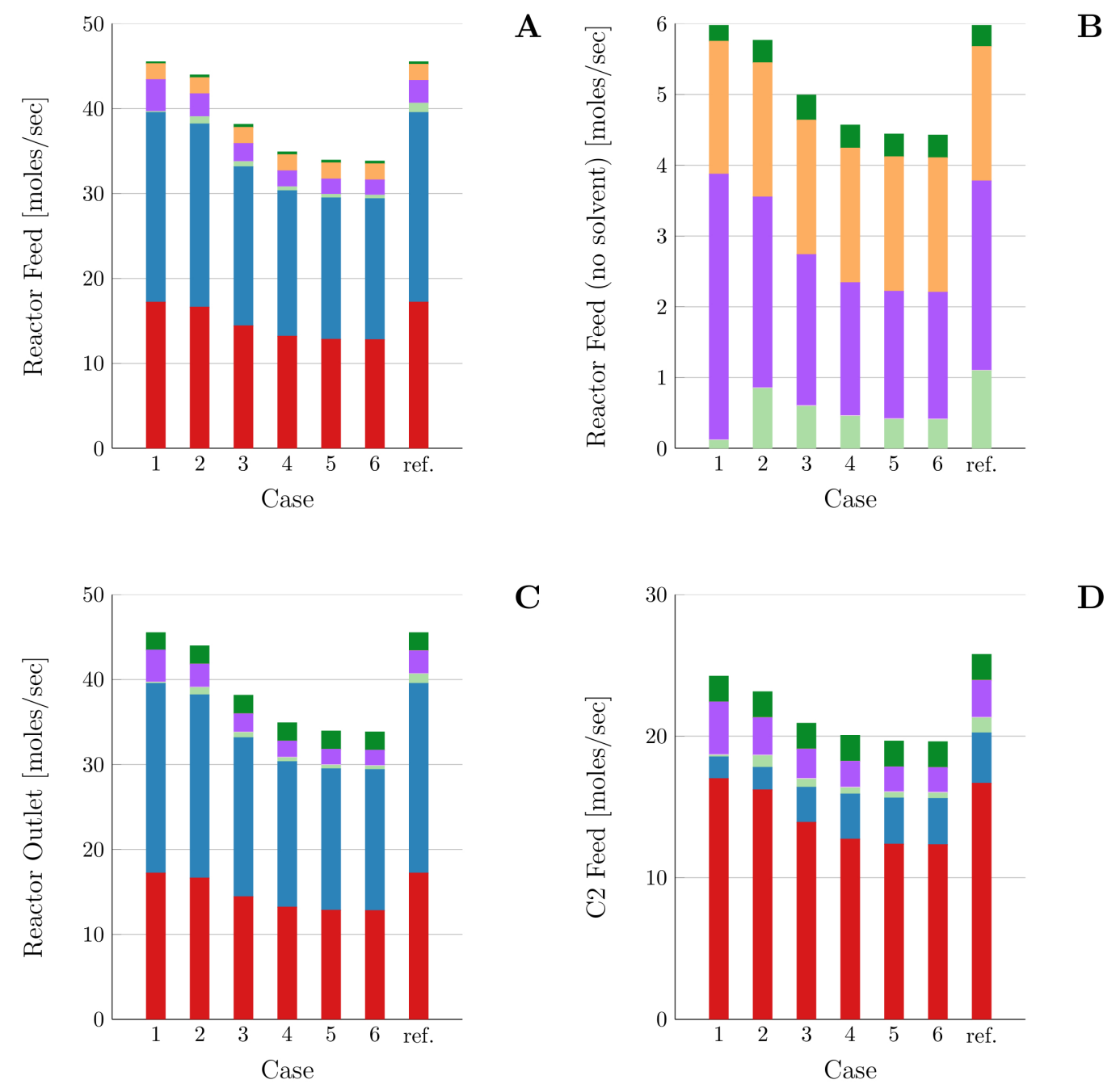

\section{C}

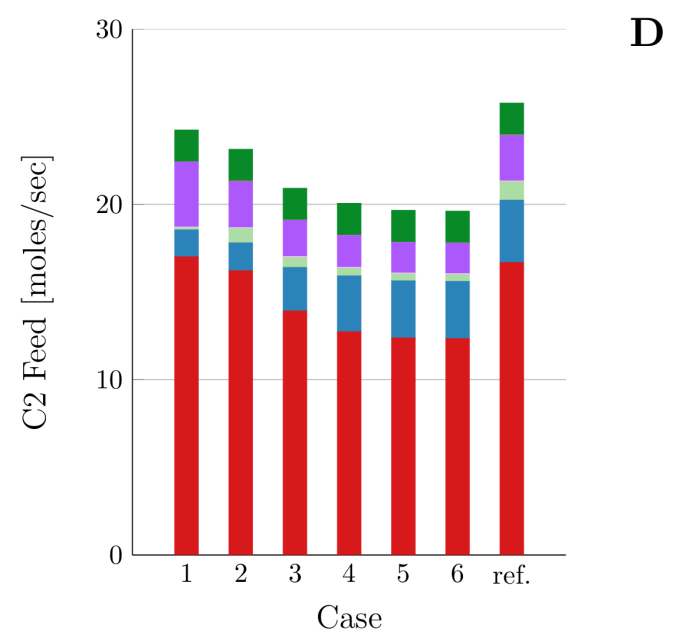

$$
\text { C10an DMF iC12en iC13al }
$$

Figure 9: Stream compositions of the reactor feed with all components (A), the reactor feed not including the TMS solvents (B), the reactor outlet (C), and the feed to the reaction solvent column, C2 (D). 


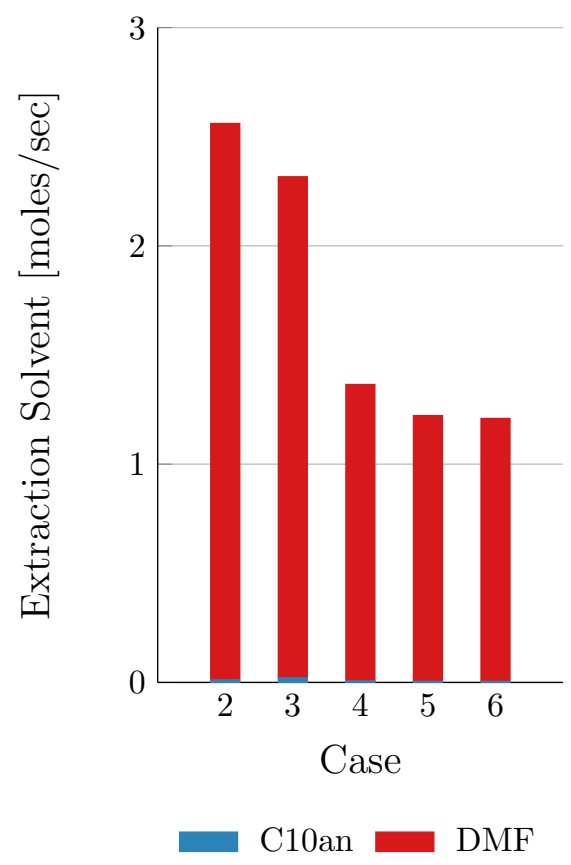

Figure 10: Extraction solvent added to the cascade. Notice the very small amounts of decane. 
Table 5: Reactor performance for the cost optimal point in each case.

\begin{tabular}{lcccccccc}
\hline & $\tau(\min )$ & $\mathrm{V}\left(\mathrm{m}^{3}\right)$ & $\mathrm{X}(\%)$ & $\mathrm{S}(\%)$ & $\frac{n}{n+i s o}$ & $\mathrm{~T}[\mathrm{~K}]$ & $\mathrm{P}_{C O}[\mathrm{bar}]$ & $\mathrm{P}_{H_{2}}[\mathrm{bar}]$ \\
\hline Case 1 & 3398 & 1457 & 99.81 & 97.07 & 97.66 & 388.15 & 16.52 & 3.48 \\
Case 2 & 1571 & 650 & 99.09 & 96.85 & 97.60 & 388.15 & 17.18 & 2.82 \\
Case 3 & 1894 & 680 & 99.28 & 96.47 & 97.31 & 388.15 & 17.15 & 2.84 \\
Case 4 & 2119 & 697 & 99.41 & 96.31 & 97.18 & 388.15 & 17.15 & 2.85 \\
Case 5 & 2204 & 705 & 99.46 & 96.25 & 97.13 & 388.15 & 17.14 & 2.86 \\
Case 6 & 2215 & 706 & 99.46 & 96.24 & 97.13 & 388.15 & 17.14 & 2.86 \\
Reference & 1377 & 590 & 98.92 & 96.91 & 97.70 & 388.15 & 17.34 & 2.66 \\
\hline
\end{tabular}

changes in reactor configuration will be small.

The reaction performances for all cases are shown in Table 5. Here it is seen that except for case 1, the general trend is for the reactor to increase slightly in size as the number of decanters increases. The most important effect is the amount of iso-dodecene in the feed which determines the length of the reverse-isomerization. This is connected to the higher recycle rate of products to the reactor feed as a result of the additional separation stages which also remove small amounts of the slightly polar aldehydes and dodecenes from the product mixture. This is one reason why the additional solvent in each decanter is small enough such that only small polar phases form, reducing the amount of material to be recycled.

The large reactor in case 1 is not primarily designed for reactor performance but for tuning the post-reaction mixture towards better separation of the catalyst. In Table 3 it can be seen in this case that the catalyst makes up slightly more than $90 \%$ of the total production cost excluding 1-dodecene. The reactor outlet has very little 1-dodecene reactant and iso-dodecene and 2-methyldodecanal byproducts. Instead, the proportion of dodecane is 40 to $110 \%$ higher than in all other cases which can be seen in Figure 9. The increase in dodecane and reduction in the other reaction products enhances the separation of the mixture in the following decanter. The desire to increase the amount of dodecane in 
case 1 can also be seen in the slightly higher $\mathrm{H}_{2}$ pressure compared to all other cases (see Table 5), but the importance of the reverse-isomerization may be more responsible for this higher partial pressure. The separation is so sensitive to the composition of this mixture, that even the total amount of dodecene in the mixture is kept low. This results in a very small recycle of iso-dodecene through the system, requiring the larger reactor to eventually convert almost all of the iso-dodecene produced in the reaction back into 1-dodecene. Tridecanal is only present due to the required production amount and its concentration in the reactor outlet is lower than in all other cases. The result of the reactor design in case 1 is similar to what Hentschel et al. (Hentschel et al., 2014) mentioned might happen with respect to optimal reactor design when taking catalyst leaching into account. This suggests that targeted reactor design for optimal performance cannot be performed when the catalyst leaching cost is high.

This also explains why little aldehyde is recycled through the reactor. Case 1 has the highest amount of tridecanal recovered as product per amount leaving the reactor at $89.1 \%$. The amount of tridecanal recovery decreases to the range of $83.7 \%$ to $85.1 \%$ in all other cases. In addition to the higher rates of tridecanal recycle due to the increased number of extraction stages, the overall composition in the first decanter for cases 2 to 6 is not as important as in case 1. Since the additional separation stages drastically reduce the amount of leaching down to similar levels as other utilities, other areas of the process become targets for cost reduction, as best seen in the comparison between reactor size and reaction solvent column size.

For the remaining cases, 2 through 6 , the size of the reactor depends more on the amount of iso-dodecene present in the feed. The amount of iso-dodecene leaving the reactor is slightly higher than the inlet amount due to the small portion lost in the purge stream. With a higher concentration of iso-dodecene in the feed, the equilibrium concentration is more quickly reached and less time for the reverse-isomerization is required. The reactor in case 2 is the smallest for all cases not including the reference. This is due to it having 
the highest amount of iso-dodecene in the reactor feed. The equilibrium concentration of iso-dodecene is quickly reached and the reverse isomerization process does not require as much time as those with lower inlet concentrations. Each reactor tries to balance the amount of iso-dodecene in the process in this way to reduce the cost of 1-dodecene in the feed and with respect to the trade-off with the size and utility demand of C2.

In all cases, the reaction temperature is maintained at the maximum of $388.15 \mathrm{~K}$. Higher reaction temperatures increase the rate of the reverse-isomerization, which is the most important aspect in determining the reactor size. Although lower temperatures are beneficial for converting 1-dodecene into tridecanal, this reaction phase is very fast compared to the reverse-isomerization and is therefore not as critical. In DSR models using EPF optimal temperature trajectories, the two temperature regions are visible; however changes in reactor size and performance are minimal. Thus isothermal conditions are satisfactory.

The partial pressures of $\mathrm{CO}$ and $\mathrm{H}_{2}$ found in each case are relatively similar, as shown in Table 5. Since higher concentrations of CO in the liquid phase lead to reductions in the isomerization, it is of no surprise that the partial of pressure of $\mathrm{CO}$ is high compared to that of $\mathrm{H}_{2}$. This leads to higher selectivities for the tridecanal product and a reduction in the 2-methyldodecanal byproduct. However, in cases where the reverse-isomerization becomes more important (as in case 1) the partial pressure of $\mathrm{H}_{2}$ tends to be higher. This is also seen in the very small increase in $\mathrm{H}_{2}$ pressures as the reactor size increases.

\section{Conclusion}

The issue of catalyst leaching in the hydroformylation of 1-dodecene has been a longstanding hindrance to reasonable economic performance. By using modern computational techniques like COSMO-RS, the expensive catalyst ligand was modeled and partition coefficients for its distribution between the phases predicted. Combining phase equilibrium calculations and catalyst partitioning ratios, a highly accurate surrogate model using the Kriging method was developed. 
Several integrated reaction extraction optimization studies were performed showing improved process economics compared to the chosen reference case. This reference case closely represents the conventional method accepted for the hydroformylation of 1-dodecene using a single stage separation of the catalyst via a TMS. The proposed decanter cascade improves the process by making better use of resources, especially the expensive catalyst, by reducing the necessary capital investment and by curtailing utility consumption. This is naturally coupled with a substantial reduction in TAC. A key tenant of process intensification is seen in the catalyst separation as well: the energy consumption of the separation decreases when using multiple decanters while the overall separation efficiency increases.

The optimization results show that by using extraction, in the form of a counter current cascade, catalyst leaching levels become almost negligible. Additional decanters eventually drive the overall process cost down towards the TAC of a reference case where catalyst loss was not considered in the objective function. This shows that extraction for catalyst recovery should not be overlooked and may provide a reasonable solution for hydroformylation of long-chain alkenes. After case 3, the optimization becomes a conventional reactor-separator problem once catalyst leaching is almost irrelevant. It is seen that with integrated reaction and separation design, it is not the reactor that always defines the separation task, but sometimes the separation task that defines the reactor. By using an extraction cascade, the robustness of the process increases as the separation becomes less dependent upon the output of the reactor. The process economics would not entirely depend upon the separation performance of a single decanter which in turn is dependent upon the composition of the post-reaction mixture. This work concludes then that the hydroformylation of 1-dodecene and other long-chain alkenes is economically feasible and more robust using a decanter cascade for increased catalyst recovery.

\subsection{Outlook}

Despite its positive characteristics as a solvent, it is generally accepted that usage of DMF needs to be reduced. The proposed decanter cascade provides a foundation for 
selection of new solvents. A different, potentially friendlier, solvent other than DMF could be identified for use as the extraction solvent. Although DMF is a satisfactory solvent for separating the catalyst from the post-reaction mixture as part of a TMS, it is not necessarily required when using several additional catalyst extractions. Thus, solvents that do not perform as well as DMF at separating the catalyst may be used for extraction in a decanter cascade similar to the one proposed. Although the solubility of the catalyst may be lower in the new solvent, several separation stages would alleviate this problem, potentially leading to a safer process. The new solvent may not even need to form a TMS, as seen in the successful hydroformylation of 1-dodecene in toluene. Naturally, the other physical properties of the new solvent would need to be investigated, such as vapor pressure etc. Thus, future work should consider identifying replacement solvents for extracting a homogeneous catalyst used in a decanter cascade as presented here.

\section{Acknowledgment}

This work was conducted in part in cooperation with the Collaborative Research Centre "Integrated Chemical Processes in Liquid Multiphase Systems". The financial support from the German Research Foundation (DFG) under the grant SFB/TRR 63 is gratefully acknowledged. The authors would also like to thank Umicore AG \& Co. KG for donating the $\mathrm{Rh}$ precursor, $\mathrm{Rh}(\mathrm{CO})_{2}$ acac.

\section{Supporting Information}

Nomenclature, pure substance properties, reaction kinetics, process flowsheet model constraints, utility and unit size models, cost functions including capital investment, utility, and materials. 


\section{References}

Behr, A., Brunsch, Y., and Lux, A. (2012). Rhodium nanoparticles as catalysts in the hydroformylation of 1-dodecene and their recycling in thermomorphic solvent systems. Tetrahedron Lett., 53(22):2680-2683.

Behr, A. and Fängewisch, C. (2002). Temperature-dependent multicomponent solvent systems-an alternative concept for recycling homogeneous catalysts. Chem. Eng. Technol., 25(2):143-147.

Behr, A., Henze, G., Johnen, L., and Awungacha, C. (2008). Advances in thermomorphic liquid/liquid recycling of homogeneous transition metal catalysts. J. Mol. Catal. A: Chem., 285(1):20-28.

Behr, A. and Johnen, L. (2010). Alternative Feedstocks for Synthesis. Wiley-VCH Verlag GmbH \& Co. KGaA.

Behr, A. and Neubert, P. (2012). Applied Homogeneous Catalysis. Wiley-VCH.

Biegler, L. T., Grossmann, I. E., and Westerberg, A. W. (1997). Systematic methods of chemical design process. Prentice Hall PTR.

Brunsch, Y. and Behr, A. (2013). Temperature-controlled catalyst recycling in homogeneous transition-metal catalysis: Minimization of catalyst leaching. Angew. Chem. Int. Ed., 52(5):1586-1589.

Caballero, J. A. and Grossmann, I. E. (2008). An algorithm for the use of surrogate models in modular flowsheet optimization. AIChE J., 54(10):2633-2650.

Cornils, B. and Herrmann, W. A. (2003). Concepts in homogeneous catalysis: the industrial view. J. Catal., 216(1):23-31. 
Dreimann, J., Lutze, P., Zagajewski, M., Behr, A., Górak, A., and Vorholt, A. J. (2016a). Highly integrated reactor-separator systems for the recycling of homogeneous catalysts. Chem. Eng. Process., 99:124-131.

Dreimann, J. M., Skiborowski, M., Behr, A., and Vorholt, A. J. (2016b). Recycling homogeneous catalysts simply via organic solvent nanofiltration: New ways to efficient catalysis. ChemCatChem.

Eckert, F. and Klamt, A. (2016). COSMOtherm, version C16, COSMOlogic GmbH \& Co. KG, Leverkusen, Germany.

Eichkorn, K., Weigend, F., Treutler, O., and Ahlrichs, R. (1997). Auxiliary basis sets for main row atoms and transition metals and their use to approximate coulomb potentials. Theor. Chem. Acc., 97:119-124.

Fang, J., Jana, R., Tunge, J. A., and Subramaniam, B. (2011). Continuous homogeneous hydroformylation with bulky rhodium catalyst complexes retained by nano-filtration membranes. Appl. Catal. A-Gen., 393(1):294-301.

Fang, J., Jin, H., Ruddy, T., Pennybaker, K., Fahey, D., and Subramaniam, B. (2007). Economic and environmental impact analyses of catalytic olefin hydroformylation in co 2 -expanded liquid (cxl) media. Ind. Eng. Chem. Res., 46(25):8687-8692.

Freund, H., Peschel, A., and Sundmacher, K. (2011). Model-based reactor design based on the optimal reaction route. Chem. Ing. Tech., 83(4):420-426.

Gross, J. and Sadowski, G. (2001). Perturbed-chain saft: An equation of state based on a perturbation theory for chain molecules. Ind. Eng. Chem. Res., 40(4):1244-1260.

Guthrie, K. M. (1969). Data and techniques for preliminary capital cost estimating. McGraw-Hill. 
Hentschel, B., Kiedorf, G., Gerlach, M., Hamel, C., Seidel-Morgenstern, A., Freund, H., and Sundmacher, K. (2015). Model-based identification and experimental validation of the optimal reaction route for the hydroformylation of 1-dodecene. Ind. Eng. Chem. $\underline{\text { Res., }}$ 54(6):1755-1765.

Hentschel, B., Peschel, A., Freund, H., and Sundmacher, K. (2014). Simultaneous design of the optimal reaction and process concept for multiphase systems. Chem. Eng. Sci., 115:69-87.

Hintermair, U., Zhao, G., Santini, C. C., Muldoon, M. J., and Cole-Hamilton, D. J. (2007). Supported ionic liquid phase catalysis with supercritical flow. Chem. Commun., (14):1462-1464.

Janssen, M., Wilting, J., Müller, C., and Vogt, D. (2010). Continuous rhodium-catalyzed hydroformylation of 1-octene with polyhedral oligomeric silsesquioxanes (poss) enlarged triphenylphosphine. Angew. Chem. Int. Edit., 49(42):7738-7741.

Kiedorf, G., Hoang, D., Müller, A., Jörke, A., Markert, J., Arellano-Garcia, H., SeidelMorgenstern, A., and Hamel, C. (2014). Kinetics of 1-dodecene hydroformylation in a thermomorphic solvent system using a rhodium-biphephos catalyst. Chem. Eng. Sci., 115:31-48.

Klamt, A., Eckert, F., and Arlt, W. (2010). COSMO-RS: An alternative to simulation for calculating thermodynamic properties of liquid mixtures. Annu. Rev. Chem. Biomol. Eng., 1:101-122.

Kleijnen, J. P. (2009). Kriging metamodeling in simulation: A review. Eur. J. Oper. Res., 192(3):707-716.

Krige, D. G. (1951). A statistical approach to some mine valuations and allied problems at the witwatersrand. Masters thesis, University of Witwatersrand, South Africa. 
Kunene, T. E., Webb, P. B., and Cole-Hamilton, D. J. (2011). Highly selective hydroformylation of long-chain alkenes in a supercritical fluid ionic liquid biphasic system. Green Chem., 13(6):1476.

Markert, J., Brunsch, Y., Munkelt, T., Kiedorf, G., Behr, A., Hamel, C., and SeidelMorgenstern, A. (2013). Analysis of the reaction network for the rh-catalyzed hydroformylation of 1-dodecene in a thermomorphic multicomponent solvent system. Appl. Catal. A-Gen., 462-463:287-295.

McBride, K., Gaide, T., Vorholt, A., Behr, A., and Sundmacher, K. (2016). Thermomorphic solvent selection for homogeneous catalyst recovery based on COSMO-RS. Chem. Eng. Process., 99:97-106.

McBride, K. and Sundmacher, K. (2015). Data driven conceptual process design for the hydroformylation of 1-Dodecene in a thermomorphic solvent system. Ind. Eng. Chem. Res., 54(26):6761-6771.

Nowothnick, H., Rost, A., Hamerla, T., Schomäcker, R., Müller, C., and Vogt, D. (2013). Comparison of phase transfer agents in the aqueous biphasic hydroformylation of higher alkenes. Catal. Sci. Technol., 3(3):600-605.

Pogrzeba, T., Müller, D., Hamerla, T., Esche, E., Paul, N., Wozny, G., and Schomäcker, R. (2015). Rhodium-catalyzed hydroformylation of long-chain olefins in aqueous multiphase systems in a continuously operated miniplant. Ind. Eng. Chem. Res., 54(48):1195311960.

Quirante, N., Javaloyes, J., and Caballero, J. A. (2015). Rigorous design of distillation columns using surrogate models based on kriging interpolation. AIChE J., pages 21692187.

Rappoport, D. and Furche, F. (2010). Property-optimized Gaussian basis sets for molecular response calculations. J. Chem. Phys., 133(13):134105. 
Schäfer, E., Brunsch, Y., Sadowski, G., and Behr, A. (2012). Hydroformylation of 1dodecene in the thermomorphic solvent system dimethylformamide/decane. Ind. Eng. Chem. Res., 51(31):10296-10306.

Schäfer, E. and Sadowski, G. (2012). Liquid-liquid equilibria of systems with linear aldehydes. experimental data and modeling with PCp-saft. Ind. Eng. Chem. Res., 51(44):1452514534.

Schwarze, M., Pogrzeba, T., Seifert, K., Hamerla, T., and Schomäcker, R. (2015). Recent developments in hydrogenation and hydroformylation in surfactant systems. Catal. Today, 247:55-63.

Subramaniam, B., Chaudhari, R. V., Chaudhari, A. S., Akien, G. R., and Xie, Z. (2014). Supercritical fluids and gas-expanded liquids as tunable media for multiphase catalytic reactions. Chem. Eng. Sci., 115:3-18.

TURBOMOLE (2013). V6.5, Program packager for ab initio electronic structure calculations, COSMOlogic GmbH \& Co. KG, Leverkusen, Germany.

Weidlich, U. and Gmehling, J. (1987). A modified UNIFAC model. 1. prediction of VLE, $\mathrm{h}^{e}$, and $\gamma^{\infty}$. Ind. Eng. Chem. Res., 26:1372-1381.

Wiese, K.-D. and Obst, D. (2006). Hydroformylation. Catalytic Carbonylation Reactions, pages $1-33$.

Xie, Z., Akien, G. R., Sarkar, B. R., Subramaniam, B., and Chaudhari, R. V. (2015). Continuous hydroformylation with phosphine-functionalized polydimethylsiloxane rhodium complexes as nanofilterable homogeneous catalysts. Ind. Eng. Chem. Res., 54(43):1065610660.

Xie, Z., Fang, J., Subramaniam, B., Maiti, S. K., Snavely, W., and Tunge, J. A. (2013). En- 
hanced hydroformylation by carbon dioxide-expanded media with soluble rh complexes in nanofiltration membrane reactors. AIChE J., 59(11):4287-4296.

Yaws, C. (1998). Chemical Properties Handbook: Physical, Thermodynamics, $\underline{\text { Environmental Transport, Safety \& Health Related Properties for Organic \& Inorganic }}$ Chemical. McGraw-Hill Professional, $1^{\text {st }}$ edition.

Zagajewski, M., Dreimann, J., and Behr, A. (2014). Verfahrensentwicklung vom labor zur miniplant: Hydroformylierung von 1-Dodecen in thermomorphen lösungsmittelsystemen. Chem. Ing. Tech., 86(4):449-457. 